Check for updates

Cite this: Mater. Adv., 2020, 1,2492

Received 18th July 2020 , Accepted 11th August 2020

DOI: 10.1039/d0ma00518e

rsc.li/materials-advances

\section{Morphology and crystal structure dependent pseudocapacitor performance of hydrated $\mathrm{WO}_{3}$ nanostructures $\dagger$}

\author{
Shobhnath P. Gupta, ${ }^{a}$ Harishchandra H. Nishad, (D) a Vandana B. Patil, ${ }^{b}$ \\ Sanjay D. Chakane, ${ }^{c}$ Mahendra A. More, ${ }^{d}$ Dattatray J. Late iD ${ }^{e}$ and \\ Pravin S. Walke iD *a
}

\begin{abstract}
The strategic morphology tuning of hydrated $\mathrm{WO}_{3}$ nanostructures from two-dimensional (2D) nanosheets to three-dimensional (3D) slabs with enhanced in-plane crystalline nature and multilayered construction is realized via tailoring the synthesis temperature. The increasing synthesis temperature expands the degree of crystallinity, specific surface area and thickness of layered $\mathrm{WO}_{3} \cdot \mathrm{H}_{2} \mathrm{O}$ sheets which results in slab like 3D morphology as characterized by X-ray diffraction spectra (XRD), Raman spectra and scanning electron microscopy (SEM). The electrochemical study reveals the higher specific capacitance (386 $\mathrm{F} \mathrm{g}^{-1}$ ) of $3 \mathrm{D}$ slabs compared to that of $2 \mathrm{D}$ nanosheets $\left(254 \mathrm{~F} \mathrm{~g}^{-1}\right.$ ) at a scan rate of $2 \mathrm{mV} \mathrm{s}^{-1}$. Moreover, 3D slabs demonstrate an excellent capacitance retention of $96 \%$ compared to 2D nanosheets (86\%) after 3000 cycles. The enhanced performance of supercapacitors in 3D slabs is attributed to three significant aspects: first, confined coordinated hydrate in the crystalline layer provides a significant surface area and allows fast electrochemical proton insertion via the Eigen-Zundel-Eigen mechanism; second, the enhanced crystalline nature offers improved in-plane conductivity; and finally the structural defects and disorders due to the layered structure promote faradaic redox reactions.
\end{abstract}

\section{Introduction}

The energy scenario at the global level is insisting on efficient efforts towards green and clean energy to fulfill the enormous demand of future generations. In this context, different energy harvesting related activities are initiated and implemented through renewable energy resources; however, the energy storage at a large scale is still challenging. Highly efficient and nextgeneration energy storage devices are required to fulfill the desire of the smart civilization, for example long-lasting portable electronic devices, ecofriendly e-vehicles and so on. ${ }^{1-4}$ Both batteries and supercapacitors are promising electrochemical energy storage devices. Remarkably, supercapacitors exhibit fascinating properties such as a fast charging-discharging rate,

\footnotetext{
${ }^{a}$ National Centre for Nanoscience's and Nanotechnology, University of Mumbai, Mumbai-400098, India.E-mail: shivshripsw@gmail.com, pravin.w@nano.mu.ac.in

${ }^{b}$ Department of Physics, Dr D.Y. Patil Institute of Engineering Management \& Research, Akurdi, Pimpri-Chinchwad, Maharashtra 411044, India

${ }^{c}$ Department of Physics, Arts, Science and Commerce College, Affiliated to Savitribai Phule Pune University, Pune-411007, Indapur, Pune-413106, India

${ }^{d}$ Department of Physics, Savitribai Phule Pune University, Pune-411007, India

${ }^{e}$ Centre for Nanoscience \& Nanotechnology, Amity University, Mumbai-410206, India

$\dagger$ Electronic supplementary information (ESI) available. See DOI: 10.1039/d0ma00518e
}

millions of life cycles and high power density compared to batteries. ${ }^{5,6}$ Nevertheless, supercapacitors have limitations in practical application because of their low energy density. ${ }^{7,8}$ The charge storage mechanisms distinguish supercapacitors into two categories: electrical double layer capacitors (EDLCs) and pseudocapacitors. ${ }^{9,10}$ The carbon electrodes are commonly used in EDLCs as they provide a greater surface area to absorb the charges without faradaic reaction at the interface between the electrode and the electrolyte. ${ }^{11,12}$ B. E. Conway has classified pseudocapacitors based on charge storage mechanisms: (1) capacitors involving underpotential deposition, where metal ions or protons adsorb on a metal surface above their redox potential, (2) redox capacitors, involving faradaic redox reactions on the surface or near the surface of electrode materials and (3) intercalated pseudocapacitors, involving fast faradaic insertion of ions into the tunnel or inter-layers of the electrode material. ${ }^{13,14}$ The pseudocapacitor type electrodes are highly demanded as a consequence of their ability to boost the energy density of supercapacitors with marginally compromised power density and cyclic life. ${ }^{15}$

Usually, the transition metal oxides (TMOs) such as $\mathrm{RuO}_{2}$, $\mathrm{MnO}_{2}, \mathrm{NiO}$, and $\mathrm{Co}_{3} \mathrm{O}_{4}$ show the pseudocapacitive charge storage mechanism and are prominently employed as cathode materials in supercapacitors. ${ }^{16-20}$ However, these cathode materials 
suffer from high cost, toxicity, low density and low conductivity for practical application. ${ }^{21,22}$ Recently, more attention has been devoted to the $\mathrm{WO}_{3}$ structure owing to the three-dimensional (3D) lattice network similar to the perovskite unit, which consists of corner and edge sharing octahedra $\left(\mathrm{WO}_{6}\right) \cdot{ }^{23,24}$ It is cost-effective and has excellent physical and chemical properties such as an n-type wide band gap, high density $\left(7.13 \mathrm{~g} \mathrm{~cm}^{-3}\right)$, various oxidation states $\left(\mathrm{W}^{2+}-\mathrm{W}^{6+}\right)$, and variable electrical conductivity $\left(10-10^{-6} \mathrm{~S} \mathrm{~cm}^{-1}\right){ }^{25,26}$ Also, $\mathrm{WO}_{3}$ exists in various crystalline phases which makes $\mathrm{WO}_{3}$ an extraordinary material amongst other TMOs for electrochromic, photocatalytic, gas sensing and electrochemical energy storage application. ${ }^{27-31}$ Moreover, the various crystal phases including trigonal tunnels and cavities are highly favorable for tuning its physical properties and electrochemical ion intercalation. ${ }^{32-35}$ Interestingly, the hydrated form of $\mathrm{WO}_{3}$ such as $\mathrm{WO}_{3} \cdot n \mathrm{H}_{2} \mathrm{O}(n=2,1,0.5,0.33)$ exhibits a two-dimensional (2D) infinite layered crystal structure as a result of confined water in the crystalline structure. ${ }^{36}$ The crystal structure can be tuned by confined hydrate; for example, the monohydrate $\mathrm{WO}_{3} \cdot \mathrm{H}_{2} \mathrm{O}$ is a distorted structure composed of two-dimensional crystal structures with appropriate van der Waals gaps between the stacks. ${ }^{37,38}$ The layer of octahedra $\left(\mathrm{WO}_{6}\right)$ is composed of four equatorial oxygen atoms to form a bridging $\mathrm{O}-\mathrm{W}-\mathrm{O}$ bond along the $a b$-plane. One of the axial positions is occupied by the coordinate hydrate $\left(\mathrm{W}-\mathrm{OH}_{2}\right)$ bonds and the opposite axial position is bounded by a terminal oxygen atom $(\mathrm{W}=\mathrm{O})$ perpendicular to the sheets (along the $c$-axis). It is impossible to build $\mathrm{W}$ bonds with adjacent layers by structural hydrate arrangement and therefore these structures possess an infinite 2D layered structure. ${ }^{39}$ These coordinated water molecules maintain the Eigen-Zundel-Eigen mechanism of rapid proton conduction as in the bulk water and improve the ion storage accessibility owing to the $2 \mathrm{D}$ layered structure..$^{40}$ Kumagai et al. demonstrated that hydrated $\mathrm{H}_{2} \mathrm{WO}_{4}$ has a capacity of $450 \mathrm{~A} \mathrm{~h} \mathrm{~kg}^{-1}$ which is much higher than that of anhydrous $\mathrm{WO}_{3}\left(180 \mathrm{~A} \mathrm{~h} \mathrm{~kg}^{-1}\right)$, but did not report the energy storage kinetics. ${ }^{41}$ Recently, Mitchell et al. have confirmed structural water within the crystalline layers that provided the rapid proton transfer kinetics. ${ }^{42}$ On the other hand, the surface redox chemistry via the terminal oxygen atom and diffusion of a proton within the hydrogen bond network of confined water layers in MXene hydrate has offered suitable faradaic reactions. ${ }^{43}$ Accordingly, the electrochemical charge storage mechanisms of electrode materials are highly subjective to their morphology, electrical conductivity and crystalline nature. ${ }^{44,45}$ The $2 \mathrm{D}$ layered crystalline $\mathrm{MoO}_{3}, \mathrm{Nb}_{2} \mathrm{O}_{5}, \mathrm{~V}_{2} \mathrm{O}_{5}$, anatase $\mathrm{TiO}_{2}$, and $\delta-\mathrm{MnO}_{2}$ with porous nature have demonstrated a highrate charge storage capability via the intercalation pseudocapacitor mechanism. ${ }^{46-51}$

In this study, we have proposed a facile strategy for the synthesis of single crystalline 2D layered crystal structures of $\mathrm{WO}_{3}$ nanostructures containing confined hydrates for supercapacitor applications. The obtained $3 \mathrm{D} \mathrm{WO}_{3}$ slabs at a synthesis temperature of $110{ }^{\circ} \mathrm{C}$ have the highest degree of crystallinity and strong bond strength compared to $2 \mathrm{D} \mathrm{WO}_{3}$ sheets prepared at $70{ }^{\circ} \mathrm{C}$ and $90{ }^{\circ} \mathrm{C}$. The morphology and crystal structure dependent electrochemical charge storage performance of 3D slabs and 2D nanosheets were investigated. Further, the proton insertion into the layered crystalline structure, i.e. a signal of intercalated pseudocapacitance, was confirmed.

\section{Materials and methods}

\subsection{Materials and reagents}

Sodium tungstate dihydrate $\left(\mathrm{Na}_{2} \mathrm{WO}_{4} \cdot 2 \mathrm{H}_{2} \mathrm{O}\right)$, concentrated sulfuric acid $\left(\mathrm{H}_{2} \mathrm{SO}_{4}\right)$ and ethanol were purchased from SD Fine Chemicals, and Whatman paper was purchased from Sigma Aldrich. All aqueous solutions were prepared using double distilled water (DDW).

\subsection{Synthesis of hydrated $\mathrm{WO}_{3}$ nanosheets}

The hydrated $\mathrm{WO}_{3} \cdot \mathrm{H}_{2} \mathrm{O}$ nanosheets were prepared by a one step wet chemical method without the addition of surfactant and varying the $\mathrm{pH}$ of the solution. Sodium tungstate $(500 \mathrm{mg})$ was slowly added into $100 \mathrm{ml}$ of aqueous $1 \mathrm{M} \mathrm{H}_{2} \mathrm{SO}_{4}$ solution, followed by stirring at room temperature for $30 \mathrm{~min}$. After stirring at room temperature, the above solution was further heated at a temperature of $70{ }^{\circ} \mathrm{C}$ for $1 \mathrm{~h}$. After this, the solution was naturally cooled down to room temperature and washed continuously with DDW and ethanol. The obtained product was dried at $80{ }^{\circ} \mathrm{C}$ for $12 \mathrm{~h}$.

For the synthesis of hydrated $\mathrm{WO}_{3} \cdot \mathrm{H}_{2} \mathrm{O}$ slabs, the reaction was carried out at higher temperatures $\left(90{ }^{\circ} \mathrm{C}\right.$ and $\left.110{ }^{\circ} \mathrm{C}\right)$, keeping the other synthesis parameters the same. The obtained final products at the synthesis temperature of $70{ }^{\circ} \mathrm{C}, 90{ }^{\circ} \mathrm{C}$ and $110{ }^{\circ} \mathrm{C}$ were named W70, W90 and W110 respectively.

\subsection{Material characterization}

The crystal structure, phase purity and microstructure were characterized by X-ray diffraction (XRD) at $\lambda=1.54056 \AA$ with $\mathrm{CuK} \alpha$ radiation (Bruker D2 phaser) and Raman spectra (Raman microscope, (Renishaw inVia). The weight loss in a sample was measured by thermogravimetric analysis using a TA 2000 thermoanalyzer. The morphological investigation was done by field emission scanning electron microscopy (FESEM) (FEG Inspect 50, FEI) and high-resolution transmission electron microscopy (HR-TEM) with selected area electron diffraction (SAED; Tecnai G2-20-TWIN TEM) operating at $300 \mathrm{kV}$. The chemical composition and various oxidation states were investigated by XPS (Al-K $\alpha$ source, PHI 5000 Versa probe scanning ESCA microprobe).

\subsection{Electrochemical measurements}

The electrochemical measurements were carried out in an Autolab PGSTAT 302N system using a three-electrode assembly. The glassy carbon was used as the working electrode, a platinum wire was used as the counter electrode and a $\mathrm{Hg} / \mathrm{HgCl}$ electrode was used as the reference electrode. An active mass of $5 \mathrm{mg}$ of the sample was dispersed in $2 \mathrm{ml}$ of water-ethanol solvent of ratio $1: 1$ and $20 \mu \mathrm{l}$ of Nafion was used as a binder and the mixture was further sonicated for $5 \mathrm{~min} .10 \mu \mathrm{l}$ of homogeneous ink was loaded on a polished working electrode and dried under 
an IR lamp for $30 \mathrm{~min}$. Aqueous $1 \mathrm{M} \mathrm{H}_{2} \mathrm{SO}_{4}$ solutions were used as an electrolyte for all electrochemical measurements. The following equations were used to calculate the specific capacitance from the $\mathrm{CV}$ and GCD curves:

$$
\begin{gathered}
C=\frac{\int_{V_{\mathrm{a}}}^{V_{\mathrm{b}}} I \mathrm{~d} V}{m V\left(V_{\mathrm{b}}-V_{\mathrm{a}}\right)} \\
C=\frac{I \Delta t}{m \Delta V}
\end{gathered}
$$

where $C$ is the specific capacitance, $I / m$ is the current density, and $\Delta t$ and $\Delta V$ are the discharge time and the operating voltage window respectively.

\section{Results and discussion}

\subsection{Structural and morphological investigations of hydrated} $\mathrm{WO}_{3}$ nanoslabs

The three hydrated $\mathrm{WO}_{3}$ nanostructures namely $\mathrm{W} 70$, W90 and W110 were synthesized at three different temperatures of $70{ }^{\circ} \mathrm{C}$, $90{ }^{\circ} \mathrm{C}$ and $110{ }^{\circ} \mathrm{C}$ respectively. The crystal structure and purity of hydrated $\mathrm{WO}_{3}$ nanostructures (W70, W90 and W110) were examined by XRD and Raman spectra (Fig. 1). The XRD pattern (Fig. 1(a)) clearly shows the monohydrate orthorhombic crystal structure of tungsten oxide $\left(\mathrm{o}-\mathrm{WO}_{3} \cdot \mathrm{H}_{2} \mathrm{O}\right)$ (JCPDS: 01:084:0886) with lattice parameters $a=5.24, b=10.71, c=5.133$ of space group Pmnb (62) at all temperatures. ${ }^{52}$ However, the sample W110 depicts the most intense diffraction (111) plane (inset of Fig. 1(a)) reflecting the higher crystalline structure compared to that of the samples W70 and W90. Furthermore, the crystalline size $(D)$ of W70, W90 and W110 was investigated by the Scherrer equation as follows:

$$
D=\frac{0.94 \times \lambda}{\beta \times \cos \theta}
$$

where $\lambda$ is $1.54056 \AA$ and 0.94 is constant for CuK $\alpha$ radiation, $\beta$ is the line broadening in radians (FWHM). The estimated crystalline sizes along the (111) plane are $35 \mathrm{~nm}, 42 \mathrm{~nm}$ and $51 \mathrm{~nm}$ for samples W70, W90 and W110 respectively. Fig. 1(b) represents the schematic of the crystal structure of $\mathrm{o}-\mathrm{WO}_{3} \cdot \mathrm{H}_{2} \mathrm{O}$. This structure clearly emphasizes the layer structure of the octahedra $\left(\mathrm{WO}_{6}\right)$ along the $a b$-plane. The four oxygen atoms are coordinated to the central $\mathrm{W}$ atoms forming a number of $\mathrm{O}-\mathrm{W}-\mathrm{O}$ bridges along the $a b$-plane and the other open axial positions, in the $c$-axis perpendicular to the $a b$-plane, are bound by terminal oxygen atoms $(\mathrm{W}=\mathrm{O})$ and hydroxyl groups $\left(\mathrm{W}-\mathrm{OH}_{2}\right)$. Therefore it is difficult to create bonding between adjacent layers to form a $2 \mathrm{D}$ infinite layered crystalline structure. The Raman spectra (Fig. 1(c)) were investigated to further evaluate the various crystalline symmetry and microstructures of samples W70, W90 and W110. The Raman spectra of the sample W110 illustrate highly intense bands at $645 \mathrm{~cm}^{-1}$ and $946 \mathrm{~cm}^{-1}$ compared to samples W90 and W70 which reveals the characteristic feature of a strong bond in sample W110. The band at $946 \mathrm{~cm}^{-1}$ corresponds to the terminal $\mathrm{W}=\mathrm{O}$ bond that arises due to the confined hydrate in the layered structure. The broad peak in the range of $500-700 \mathrm{~cm}^{-1}$ illustrates the stretching mode of the bridging $\mathrm{O}-\mathrm{W}-\mathrm{O}$ bond in the $a b$-plane, as expected (a)

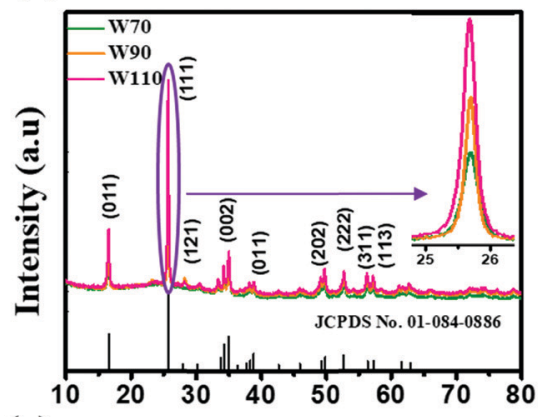

(c)

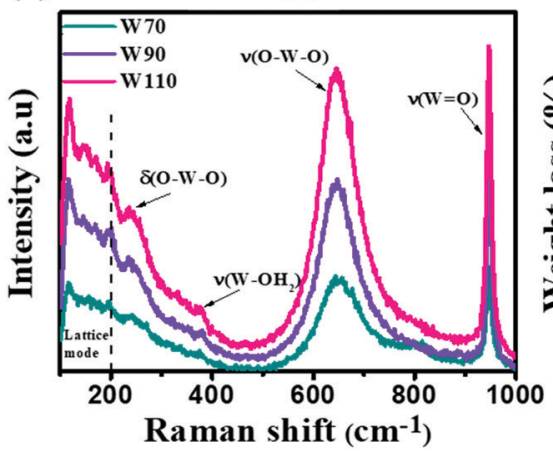

(b)

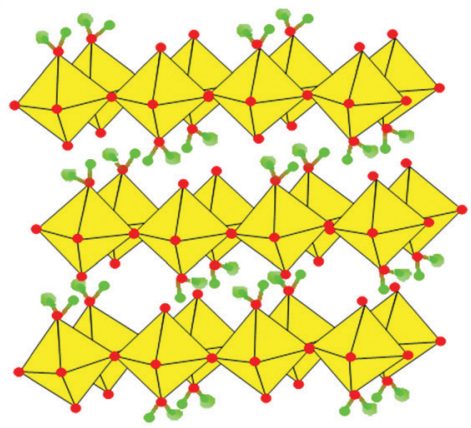

(d)

$\mathrm{WO}_{3} \cdot \mathrm{H}_{2} \mathrm{O}$

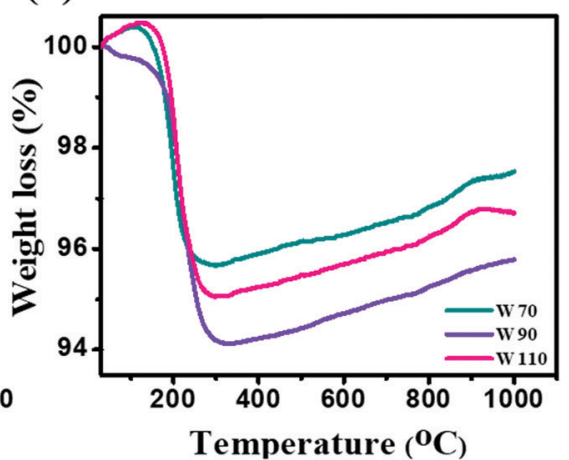

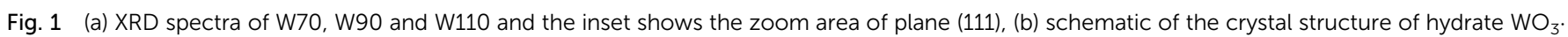
$\mathrm{H}_{2} \mathrm{O}$, (c) Raman spectra of W70, W90 and W110, (d) TGA plots of W70, W90 and W110. 
from the $2 \mathrm{D}$ structure of the $\mathrm{WO}_{3} \cdot \mathrm{H}_{2} \mathrm{O}$ network. The translational motion of the hydrogen atom in octahedral $\mathrm{WO}_{5}-\mathrm{OH}_{2}$ was assigned to a band at $370 \mathrm{~cm}^{-1}$. The band below $200 \mathrm{~cm}^{-1}$ corresponds to the lattice mode. ${ }^{53}$ The TGA curve (Fig. 1(d)) confirms the weight loss of coordinated water molecules around a temperature of $200{ }^{\circ} \mathrm{C}$ in agreement with previously reported temperature and approving the monohydrate $\mathrm{WO}_{3}$ structure. ${ }^{54}$

The synthesis temperature has a tremendous impact on morphological and structural change owing to the growth kinetics without alteration of $\mathrm{pH}$ and the addition of surfactant. The morphological analysis of samples W70, W90 and W110 was performed by FESEM (Fig. 2). The low-resolution image of W70 (Fig. 2(a)) shows a bunch of nanosheets like architecture. Furthermore, the high-resolution FESEM images (Fig. 2(b)) show the average thickness of a sheet to be in the range of 30-40 $\mathrm{nm}$. Further, on increasing the synthesis temperature to $90{ }^{\circ} \mathrm{C}$ (W90) the thickness of the nanosheets increases to 60-100 nm as shown in Fig. 2(c) and (d). Moreover, at a high synthesis temperature of $110{ }^{\circ} \mathrm{C}$, a densely packed 3D slab like morphology is created (Fig. 2(e)) and the high resolution FESEM image (Fig. 2(f)) displays that the thickness of the slabs increases to 200-250 $\mathrm{nm}$. These slabs are made up of an attachment of 4-5 nanosheets together along the surface side with exposed top edges. Furthermore, the low-magnification TEM image of the sample W110 (Fig. 3(a)) illustrates the

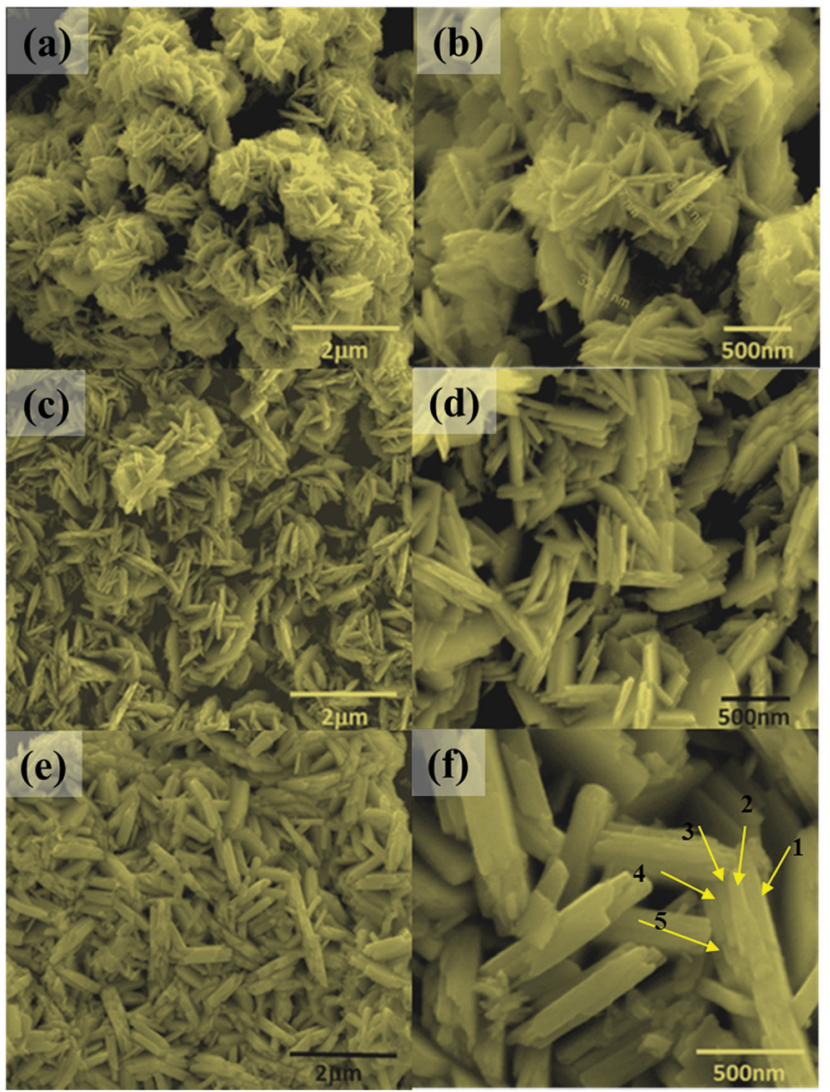

Fig. 2 ( $a$ and b) Low and high magnification FESEM images of nanosheets (W70), (c and d) low and high magnification images of nanosheets (W90), (e and f) low and high magnification images of the slab (W110).

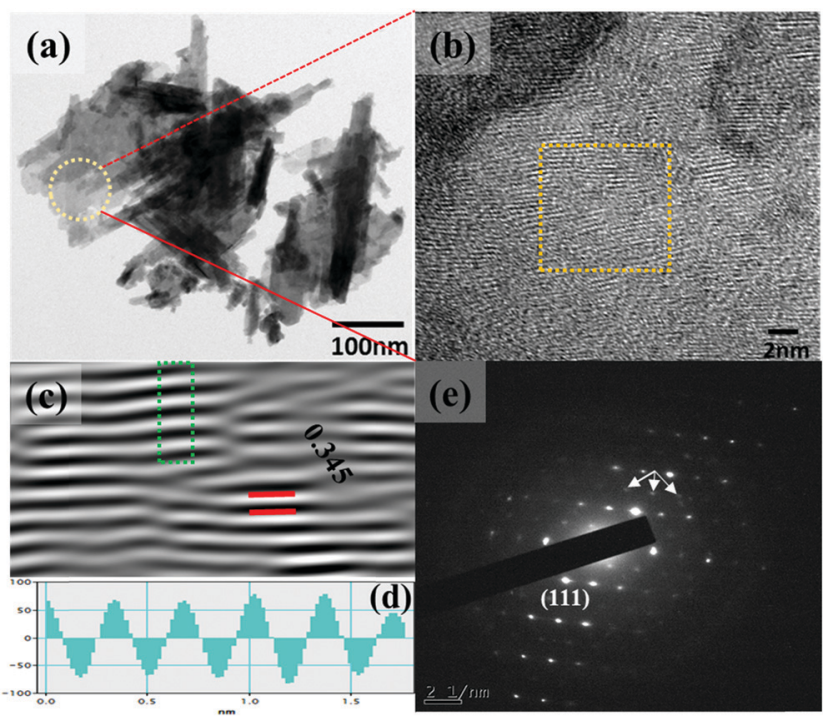

Fig. 3 ( $a$ and b) Low and high magnification TEM images of the slab (W110), (c) IFFT images, (d) intensity profile of the selected region of figure (c), (e) SAED pattern of W110.

fragmented sheets affected by sonication. The HRTEM image (Fig. 3(b)) shows an interplanar spacing of $0.345 \mathrm{~nm}$ which corresponds to the d spacing of the (111) plane. The inverse fast Fourier transform (IFFT) images (Fig. 3(c)) of the selected region of Fig. 3(b) signify the various defects such as frank disorder and stacking fault. These defects have a strong impact on the stress and electrostatic repulsion between the layers, which can directly alter the migration energy or diffusion barriers that a proton or alkali ion must overcome during intercalation. Fig. 3(d) represents the intensity profile of Fig. 3(c). The SAED pattern (Fig. 3(e)) illustrates the set of bright diffraction spots indicating the single crystalline nature of sample W110 and the SAED pattern can be an index of the (001) zone axis of orthorhombic $\mathrm{WO}_{3} \cdot \mathrm{H}_{2} \mathrm{O}$. It is also observed that, along with the strong electron diffraction spot such as (111), weak diffraction spots can also be noted at those forbidden sites which are indicated by a white arrow. These weak spots are assigned to diffraction from the higher order Laue zone due to the combination of elongation of the diffraction spot along the normal of slabs and the larger (001) atomic spacing.

The chemical composition and various oxidation states of $\mathrm{WO}_{3}$ nanoslabs (W110) were examined by XPS as shown in Fig. 4. The wide range survey scans of $\mathrm{WO}_{3}$ (Fig. S1, ESI $\dagger$ ) show the presence of $\mathrm{W}$ and $\mathrm{O}$. Moreover, the deconvoluted XPS spectra of doublet $\mathrm{W}(4 \mathrm{f})$ comprising of $\mathrm{W} 4 \mathrm{f}_{7 / 2}$ and $\mathrm{W} 4 \mathrm{f}_{5 / 2}$ at a binding energy of $35.6 \mathrm{eV}$ and $37.63 \mathrm{eV}$ show spin-orbit splitting of the $\mathrm{W}$ (4f) level and correspond to the $\mathrm{W}^{6+}$ state (Fig. 4(a)). Nevertheless, the low-intensity peaks at $33.92 \mathrm{eV}$ and $37.21 \mathrm{eV}$ demonstrate the presence of $\mathrm{W}^{5+}$ state, which illustrates the existence of oxygen vacancy in the $\mathrm{WO}_{3}$ matrix. Furthermore, the deconvoluted spectra of $\mathrm{O} 1 \mathrm{~s}$ (Fig. 4(b)) show two peaks at $531.1 \mathrm{eV}$ and $531.9 \mathrm{eV}$ which are assigned to the presence of lattice oxygen $\left(\mathrm{O}^{2-}\right)$ and adsorbed oxygen $\left(\mathrm{O}^{-}\right.$and $\left.\mathrm{O}_{2}^{-}\right)$. These multi-oxidation states of $\mathrm{W}$ and surface oxygen attributed to the enhanced electrochemical 
(a)

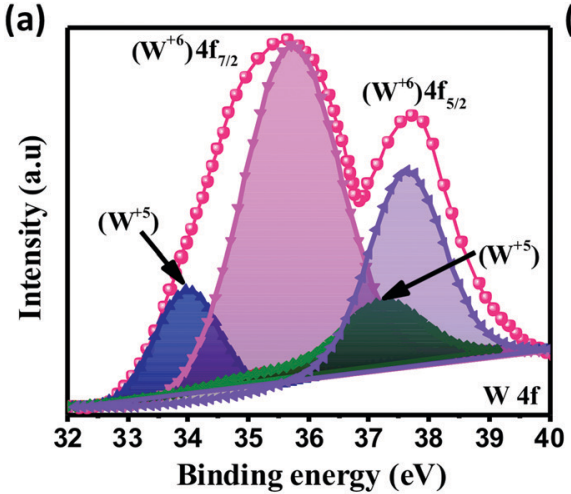

(b)

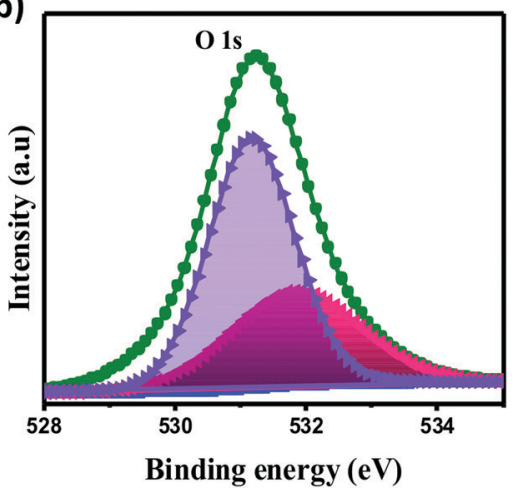

Fig. 4 XPS spectra of $\mathrm{WO}_{3}$ nanoslabs (W110): deconvoluted spectra of $\mathrm{W} 4 \mathrm{f}(\mathrm{a})$ and $\mathrm{O}$ 1s (b).

properties of $\mathrm{WO}_{3}$ slabs. ${ }^{55}$ The porosity and surface area of $\mathrm{W} 70$, W90 and W110 were examined by Brunauer-Emmett-Teller (BET) analysis (Fig. 5). The samples W110, W90 and W70 exhibit the same Langmuir(III) nitrogen adsorption-desorption isotherm with a surface area of $68.8 \mathrm{~m}^{2} \mathrm{~g}^{-1}, 49.3 \mathrm{~m}^{2} \mathrm{~g}^{-1}$ and $34.8 \mathrm{~m}^{2} \mathrm{~g}^{-1}$ respectively. The pore size distribution of the same sample was investigated by the Barrett-Joyner-Halenda (BJH) method as shown in the inset of Fig. 5. This illustrates the micro-porous nature with the pore size in the range of 1-3 nm. Thus, the high surface area of sample W110 ensures active sites for an effective electrochemical process and enhanced rate performance with storage capability. ${ }^{56}$

\subsection{Electrochemical performance of hydrated $\mathrm{WO}_{3}$ nanoslabs}

The electrochemical performance measurement of electrodes W70, W90 and W110 was carried out on a three-electrode system in a $1 \mathrm{M} \mathrm{H}_{2} \mathrm{SO}_{4}$ electrolyte between potential windows -0.6 and 0 V. Fig. 6(a) shows the superimposed cyclic voltammetry (CV) curve of electrodes W70, W90 and W110 at a low scan rate of $2 \mathrm{mV} \mathrm{s}^{-1}$. It displays the higher current contribution of W110 with greater area under the curve indicating the better electrochemical charge storage performance compared to electrodes W70 and W90. However, the electrodes W110 and

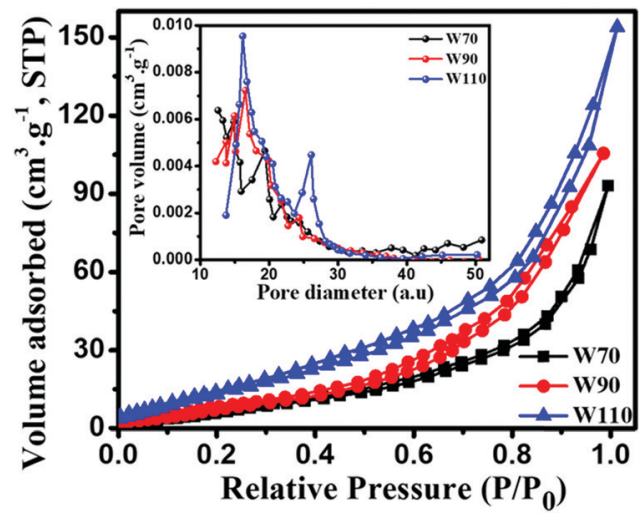

Fig. 5 Nitrogen adsorption-desorption isotherm and the inset shows the pore size distribution of W70, W90 and W110; the pore diameter unit is (a.u.) = ^ (Angstrom).
W90 are more faradaic in nature than electrode $\mathrm{W} 70$, revealing the high pseudocapacitive charge storage mechanism. The resulting anodic and cathodic waves at a low scan rate of $2 \mathrm{mV} \mathrm{s}^{-1}$ in the potential range of $-0.45 \mathrm{~V}$ to $-0.35 \mathrm{~V}$ and $-0.35 \mathrm{~V}$ to $-0.5 \mathrm{~V}$ of $\mathrm{W} 90$ and $\mathrm{W} 110$ indicate the more active surface sites and the reversible redox reaction $\mathrm{W}^{5+} / \mathrm{W}^{6+}$ accompanied with a dominant proton $\left(\mathrm{H}^{+}\right)$insertion/de-insertion pseudocapacitive process. ${ }^{57-59}$ Fig. S2 (ESI $\dagger$ ) shows the CV curves at various scan rates from 2 to $100 \mathrm{mV} \mathrm{s}^{-1}$ of electrodes W70, W90 and W110. It demonstrates that at a high scan rate of $100 \mathrm{mV} \mathrm{s}^{-1}$ the cathodic and anodic redox waves fade out due to the fast movement of protons under the high scan rate ensuing less interaction time at the electrode surface and/or low intercalation into $\mathrm{WO}_{3}$ crystalline layers. ${ }^{55}$ The comparison of specific capacitance of W70, W90 and W110 samples at various scan rates is shown in Fig. 6(b). At a lower scan rate of $2 \mathrm{mV} \mathrm{s}^{-1}$, the specific capacitance of electrode $\mathrm{W} 110$ reached $386 \mathrm{~F} \mathrm{~g}^{-1}$, which is higher than the specific capacitance of $315 \mathrm{~F} \mathrm{~g}^{-1}$ and $254 \mathrm{~F} \mathrm{~g}^{-1}$ of $\mathrm{W} 90$ and W70 respectively. This highest specific capacitance of the electrode W110 is compared with the various structures of $\mathrm{WO}_{3}$ as listed in Table 1. Similarly, the galvanostatic charge-discharge (GCD) curves were recorded at various current densities from $1 \mathrm{~A} \mathrm{~g}^{-1}$ to $10 \mathrm{~A} \mathrm{~g}^{-1}$ as shown in Fig. S3 (ESI $\dagger$ ). These GCD curves demonstrated the deviation from the triangular line in the potential range $-0.3 \mathrm{~V}$ to $-0.5 \mathrm{~V}$, implying that the capacity mainly arises by faradaic redox reactions confirming the CV findings. Fig. 6(c) shows the discharge profile at a current density of $2 \mathrm{~A} \mathrm{~g}^{-1}$, which presents the highest discharge time of electrode W110 signifying the highest storage capacity compared to W70 and W90. In comparison, the electrode W110 shows the highest specific capacitance of $367 \mathrm{~F} \mathrm{~g}^{-1}$ compared to W90 $\left(310 \mathrm{~F} \mathrm{~g}^{-1}\right)$ and W70 $\left(241 \mathrm{~F} \mathrm{~g}^{-1}\right)$ at a high current density of $1 \mathrm{~A} \mathrm{~g}^{-1}$ (Fig. 6(d) and Fig. S3(d), ESI $\dagger$ ). Interestingly, the capacitance values estimated from CV and GCD do not show any significant change in specific capacitance.

\subsection{Charge storage kinematics}

The current contribution in the $\mathrm{CV}$ curve is related to the respective scan rate according to eqn (4):

$$
I=a \times \nu^{b}
$$


(a)

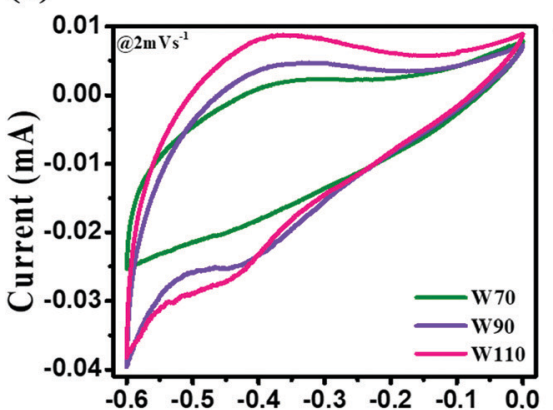

(c)

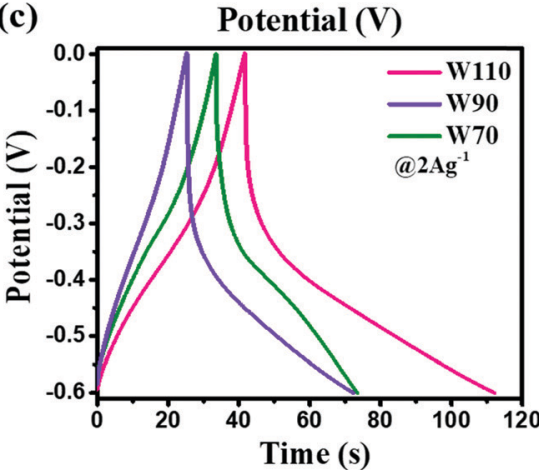

(b)

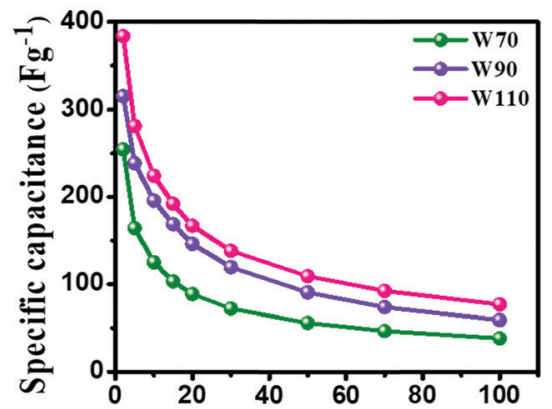

(d)
Scan rate $\left(\mathrm{mVs}^{-1}\right)$

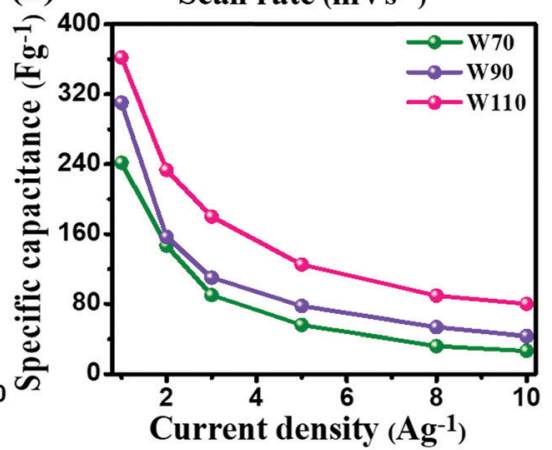

Fig. 6 (a) Comparison of the CV curve of W70, W90 and W110 at a scan rate of $2 \mathrm{mV} \mathrm{s}^{-1}$, (b) specific capacitance at various scan rates, (c) galvanostatic discharge curves of W70, W90 and W110 at a current density of $2 \mathrm{~A} \mathrm{~g}^{-1}$, (d) specific capacitance at various current densities.

Table 1 Performance comparison of various nanostructure and crystal structure of $\mathrm{WO}_{3}$

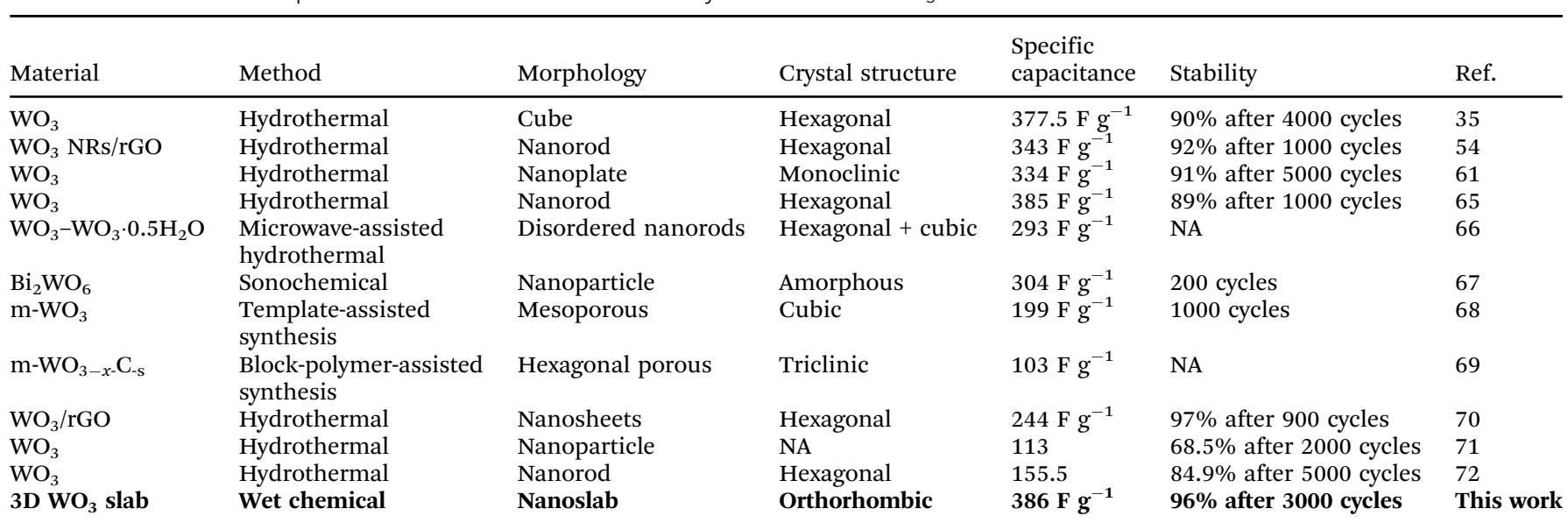

where $I$ is the current, $a$ is a constant, $\nu$ is the scan rate and $b$ is a constant value which can be 0.5 or 1 . The $b$-value is evaluated by the slope of linear fitting of $\log$ (current, $I) v s$. $\log$ (scan rate, $\nu$ ). The dependency of current in the CV curve could be varied as either $\nu^{0.5}$ or $\nu$, which represents the semi-infinite diffusion process or the dominant capacitive charge storage kinetics respectively. ${ }^{60}$ The electrode W110 shows the lowest anodic $b$-value (Fig. 7(a)) of 0.84 compared to electrodes W70 and W90 (1.2 and 1.1 respectively). Moreover, the electrode W110 clearly demonstrates the lowest $b$-value at various potential ranges of $-0.1 \mathrm{~V}$ to $-0.6 \mathrm{~V}$ (Fig. 7(b)) compared to electrodes W70 and W90. It confirms the significant proton insertion into the $2 \mathrm{D}$ structure of the slab (W110). Therefore, the highest specific capacitance of the slab (W110) compared to the nanosheets (W70 and W90) originating from the dominant proton insertion/ deinsertion into the crystalline layer has been realized. Furthermore, the Trasatti procedure has been utilized to derive the current contributions by EDLC and proton insertion from the total capacitance using eqn (5): ${ }^{61,62}$

$$
Q(\nu)=Q_{\mathrm{c}}+k \nu^{-1 / 2}
$$

where $Q_{\mathrm{c}}$ is the capacitance contribution from EDLC, $k$ is a constant, $\nu$ is the scan rate and $Q(\nu)$ is the charge storage at scan rate $\nu$. The charge storage due to EDLC across the interface of electrode and electrolyte $\left(Q_{\mathrm{c}}\right)$ was evaluated by the intercept of the plot of $Q(\nu) v s . \nu^{-1 / 2}$ (Fig. S4, ESI $\dagger$ ), and is almost $25 \mathrm{C} \mathrm{g}^{-1}$, 
(a)

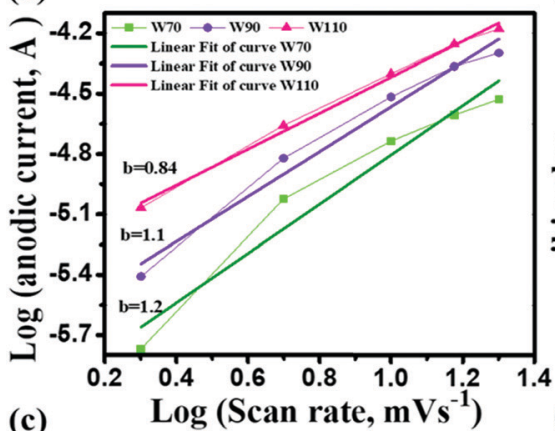

(c)

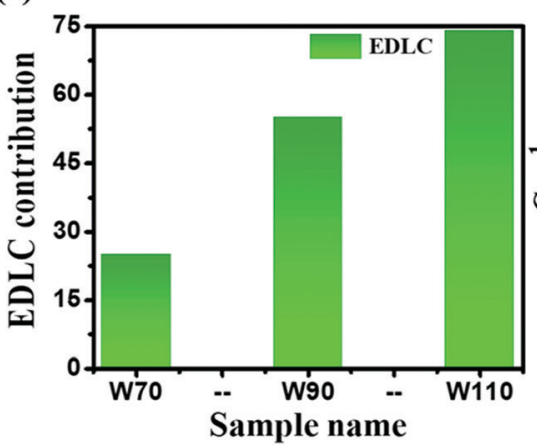

(b)

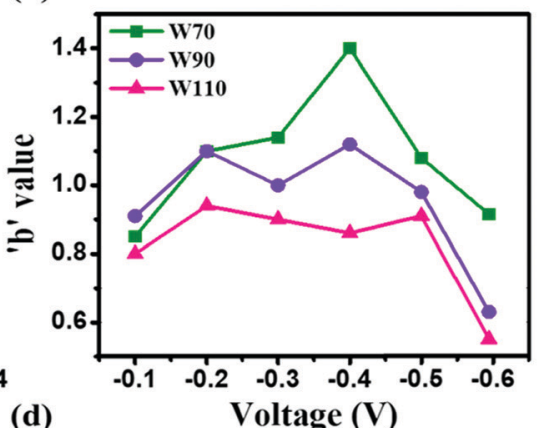

(d)

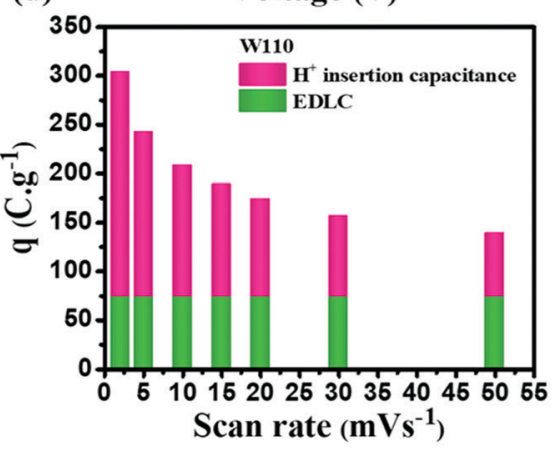

Fig. 7 Charge storage kinematics: (a) anodic peak potential $b$-values, (b) $b$-values calculated at various potentials, (c) EDLC contribution by W70, W90 and W110, (d) EDLC and $\mathrm{H}^{+}$ion insertion contributions of electrode $\mathrm{W} 110$ at various scan rates.

$55 \mathrm{C} \mathrm{g}^{-1}$ and $74 \mathrm{C} \mathrm{g}^{-1}$ for electrodes W70, W90 and W110 (Fig. 7(c)) respectively. The highest value of $Q_{c}$ for electrode W110 correlated to its high surface area compared to W70 and W90. Moreover, the proton insertion contribution of electrodes with respect to the scan rate can be evaluated by subtracting the surface stored charge values from the total stored charges at various scan rates as shown in Fig. 7(d). Based on this, the capacity due to proton insertion into the crystalline layer is found to be $230 \mathrm{C} \mathrm{g}^{-1}$ which is four times higher than EDLC contribution $\left(75 \mathrm{C} \mathrm{g}^{-1}\right)$ at a low scan rate of $2 \mathrm{mV} \mathrm{s}^{-1}$. However, at a high scan rate of $50 \mathrm{mV} \mathrm{s}^{-1}$ the proton insertion capacity is found to be $54 \mathrm{C} \mathrm{g}^{-1}$ which highlights that the proton insertion pseudocapacitance is promising at a low scan rate than at a high scan rate. ${ }^{63,64}$

Additionally, the cyclic stability test of electrodes W70, W90 and W110 was carried out using galvanostatic charge discharge (GCD) at a high current density of $5 \mathrm{~A} \mathrm{~g}^{-1}$ as shown in Fig. 8(a). The electrode W110 shows comparatively a high capacitance retention of $96 \%$ than W90 (89\%) and W70 (86\%) after 3000 cycles. It is noted that no significant variation in cyclic stability was observed in electrodes W70, W90 and W110 due to the advantage of the morphology and role of the confined hydrate in the crystallinelayered structure which enables the rapid movement of a proton. Furthermore, to better understand the charge transfer mechanism across the interface of electrode-electrolyte of all samples, electrochemical impedance spectroscopy (EIS) was carried out (Fig. S5, ESI $\dagger)$. The obtained electrochemical series resistance $\left(R_{\mathrm{ESR}}\right)$ in the high frequency region is $3.2 \Omega, 2.4 \Omega$, and $1.09 \Omega$ for W70, W90 and W110 respectively. On the other hand, the electrodes W70 and W90 exhibit a semi-circle (Fig. 8(b)) representing charge transfer resistance $\left(R_{\mathrm{ct}}\right)$ across the interface of electrode-electrolyte, which is (a)

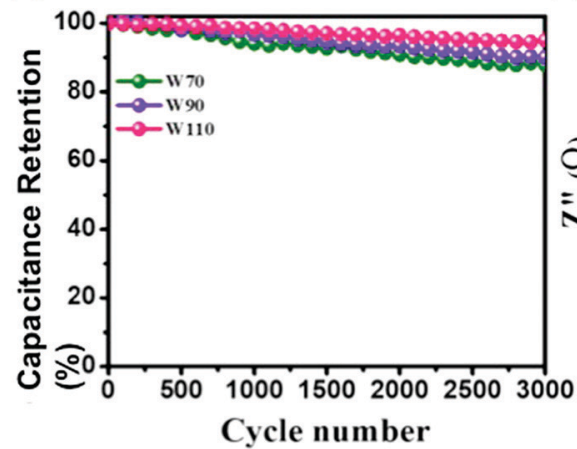

(b)

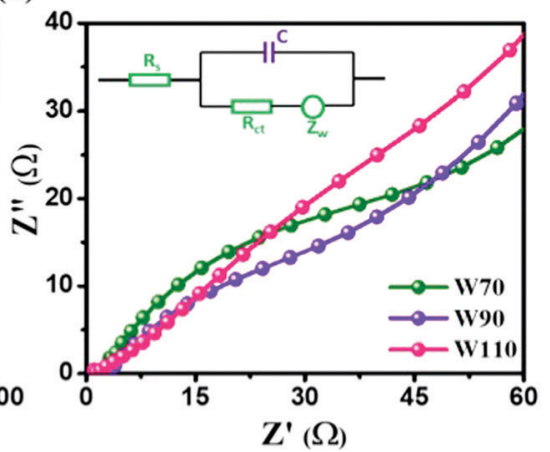

Fig. 8 (a) Cyclic stability, (b) impedance plot in the high frequency region and the inset is an equivalence circuit diagram of W70, W90 and W110. 
$54 \Omega$ and $36 \Omega$ respectively. The inset of Fig. 8(b) shows the equivalence circuit diagram with the impedance and resistance contributions to the electrochemical system. Interestingly, the slab (electrode W110) inhibits $R_{\text {ct }}$ with lower $R_{\mathrm{ESR}}$ demonstrating the smaller internal resistance and resulting in the faster kinetics of the redox reaction with high conductivity compared to electrodes W70 and W90.

\section{Conclusion}

In summary, tuning the morphology and crystallinity from hydrated $\mathrm{WO}_{3}$ nanosheets to high crystalline hydrated $\mathrm{WO}_{3}$ slabs via increasing the synthesis temperature from 70 to $110{ }^{\circ} \mathrm{C}$ is successfully achieved. The obtained 3D hydrated $\mathrm{WO}_{3}$ slabs exhibit an enhanced specific capacitance of $386 \mathrm{~F} \mathrm{~g}^{-1}$ than $2 \mathrm{D}$ hydrated $\mathrm{WO}_{3}$ nanosheets $\left(254 \mathrm{~F} \mathrm{~g} \mathrm{~g}^{-1}\right)$ at a scan rate of $2 \mathrm{mV} \mathrm{s}^{-1}$. This improved performance of hydrated $\mathrm{WO}_{3}$ slabs is attributed to the enriched crystalline structure, increased surface area, enhanced active surface sides and effective proton insertion into the layered structure, resulting in the high redox pseudocapacitive mechanism. Therefore, the $3 \mathrm{D}$ highly crystalline $\mathrm{WO}_{3}$ with confined hydrate in the layered structure is a potential candidate for high-rate intercalated pseudocapacitors.

\section{Conflicts of interest}

The authors declare no conflict of interest.

\section{Acknowledgements}

The authors would like to thank the Director, National Centre for Nanosciences and Nanotechnology, and the Vice-Chancellor, Amity University, Mumbai, for their support and help.

\section{References}

1 S. Sorrell, Renewable Sustainable Energy Rev., 2015, 47, 74-82.

2 S. Chu and A. Majumdar, Nature, 2012, 488, 294.

3 J. R. Miller and P. Simon, Science, 2012, 321, 651.

4 Q. Zhu, D. Zhao, M. Cheng, J. Zhou, K. A. Owusu, L. Mai and Y. Yu, Adv. Energy Mater., 2019, 9, 1901081.

5 B. Li, F. Dai, Q. Xiao, L. Yang, J. Shen, C. Zhang and M. Cai, Energy Environ. Sci., 2016, 9, 102-106.

6 Q. Wang, J. Yan and Z. Fan, Energy Environ. Sci., 2016, 9, 729-762, DOI: 10.1039/C5EE03109E.

7 H. Liang, C. Xia, A. Emwas, D. H. Anjum, X. Miao and N. Husam, Nano Energy, 2018, 49, 155-162.

8 X. Li, C. Zhang, S. Xin, Z. Yang, Y. Li, D. Zhang and P. Yao, ACS Appl. Mater. Interfaces, 2016, 8, 21373-21380.

9 S. R. Suryawanshi, V. Kaware, D. Chakravarty, P. S. Walke, M. A. More, K. Joshi, C. S. Rout and D. J. Late, $R S C A d v$, 2015, 5, 80990-80997.

10 B. D. Patrice Simon and Y. Gogotsi, Science, 2014, 343, 1210-1211.
11 F. Yao, T. Pham and Y. Hee, ChemSusChem, 2015, 8, 2284-2311.

12 Y. Hao, F. Xu, M. Qian, J. Xu, W. Zhao and F. Huang, RSC Adv., 2017, 7, 10901-10905.

13 V. Augustyn, P. Simon and B. Dunn, Energy Environ. Sci., 2014, 7, 1597-1614.

14 Y. Wang, Y. Song and Y. Xia, Chem. Soc. Rev., 2016, 45, 5925-5950.

15 J. Shen, C. Yang, X. Li and G. Wang, ACS Appl. Mater. Interfaces, 2013, 5, 8467-8476.

16 V. K. A. Muniraj, C. K. Kamaja and M. V. Shelke, ACS Sustainable Chem. Eng., 2016, 4, 2528-2534.

17 Y. Song, T. Liu, B. Yao, M. Li, Z. Huang, D. Feng, F. Wang, Y. Tong, X. Liu and Y. Li, ACS Energy Lett., 2017, 2(17), 1752-1759, DOI: 10.1021/acsenergylett.7b00405.

18 X. L. Guo, J. M. Zhang, W. N. Xu, C. G. Hu and L. Sun, J. Mater. Chem. A, 2017, 5, 20579-20587.

19 X. Xia, J. Tu, Y. Zhang, Y. Mai, X. Wang, C. Gu and X. Zhao, RSC Adv., 2012, 2, 1835-1841.

20 Y. Zeng, M. Yu, Y. Meng, P. Fang, X. Lu and Y. Tong, Adv. Energy Mater., 2016, 6, 1601053.

21 Z. Xu, S. Sun, W. Cui, J. Lv, Y. Geng, H. Li and J. Deng, Electrochim. Acta, 2018, 268, 340-346.

22 M. V. K. Azhagan, M. V. Vaishampayan and M. V. Shelke, J. Mater. Chem. A, 2014, 2, 2152-2159.

23 H. Zheng, J. Z. Ou, M. S. Strano, R. B. Kaner, A. Mitchell and K. Kalantar-Zadeh, Adv. Funct. Mater., 2011, 21, 2175-2196.

24 L. M. Kuti, S. S. Bhella and V. Thangadurai, Inorg. Chem., 2009, 48, 6804-6811.

25 R. Samal, B. Chakraborty, M. Saxena, D. J. Late and C. S. Rout, ACS Sustainable Chem. Eng., 2019, 7, 2350-2359.

26 P. A. Shinde and S. C. Jun, ChemSusChem, 2020, 13, 11-38.

27 Y. M. Shirke and S. P. Mukherjee, CrystEngComm, 2017, 19, 2096-2105.

28 A. K. Nayak, S. Lee, Y. I. Choi, H. J. Yoon, Y. Sohn and D. Pradhan, ACS Sustainable Chem. Eng., 2017, 5, 2741-2750.

29 J. Besnardiere, B. Ma, A. Torres-pardo, G. Wallez, H. Kabbour, J. M. González-calbet, H. J. Von Bardeleben, B. Fleury, V. Buissette, C. Sanchez, T. Le Mercier, S. Cassaignon and D. Portehault, Nat. Commun., 2019, 10, 327.

30 S. S. Kalanur, Y. J. Hwang, S. Y. Chae and O. S. Joo, J. Mater. Chem. A, 2013, 1, 3479-3488.

31 Z. Chen, Y. Peng, F. Liu, Z. Le, J. Zhu, G. Shen, D. Zhang, M. Wen, S. Xiao, C. P. Liu, Y. Lu and H. Li, Nano Lett., 2015, 15, 6802-6808.

32 M. Zhu, W. Meng, Y. Huang, Y. Huang and C. Zhi, ACS Appl. Mater. Interfaces, 2014, 6, 18901-18910.

33 J. Cao, B. Luo, H. Lin, B. Xu and S. Chen, Appl. Catal., B, 2012, 111-112, 288-296.

34 W. Sun, M. T. Yeung, A. T. Lech, C. Lin, C. Lee, T. Li, X. Duan, J. Zhou and R. B. Kaner, Nano Lett., 2015, 15, 4834-4838.

35 V. Lokhande, A. Lokhande, G. Namkoong, J. H. Kim and T. Ji, Results Phys., 2019, 12, 2012-2020.

36 Y. M. Li, M. Hibino, M. Miyayania and T. Kudo, Solid State Ionics, 2000, 134, 271-279.

37 J. Zheng, Z. Haider, T. K. Van, A. U. Pawar, C. Kang and Y. Kang, CrystEngComm, 2015, 17, 6070-6093, DOI: 10.1039/ C5CE00900F. 
38 B. Kattouf, G. L. Frey, A. Siegmann and Y. Ein-Eli, Chem. Commun., 2009, 7396-7398.

39 L. Liang, J. Zhang, Y. Zhou, J. Xie, X. Zhang, M. Guan, B. Pan and Y. Xie, Sci. Rep., 2013, 3, 1936.

40 J. B. Mitchell, W. C. Lo, A. Genc, J. Lebeau and V. Augustyn, Chem. Mater., 2017, 29, 3928-3937.

41 N. Kumagai, N. Kumagai and K. Tanno, Appl. Phys. A: Mater. Sci. Process., 1989, 89, 83-89.

42 J. B. Mitchell, N. R. Geise, A. R. Paterson, N. C. Osti, Y. Sun, S. Fleischmann, R. Zhang, L. A. Madsen, M. F. Toney, D. E. Jiang, A. I. Kolesnikov, E. Mamontov and V. Augustyn, ACS Energy Lett., 2019, 4, 2805-2812.

43 Y. Sun, C. Zhan, P. R. C. Kent, M. Naguib, Y. Gogotsi and D. Jiang, ACS Appl. Mater. Interfaces, 2019, 12, 763-770.

44 T. Brousse, M. Toupin, R. Dugas, L. Athouël, O. Crosnier, T. Brousse, M. Toupin, R. Dugas, L. Athouël, O. Crosnier and D. Bélanger, J. Electrochem. Soc., 2006, 153, A2171-A2180.

45 H. Kim, J. B. Cook, H. Lin, J. S. Ko, S. H. Tolbert, V. Ozolins and B. Dunn, Nat. Mater., 2016, 16, 454-460.

46 T. Brezesinski, J. Wang, S. H. Tolbert and B. Dunn, Nat. Mater., 2010, 9, 146-151.

47 V. Augustyn, J. Come, M. A. Lowe, J. W. Kim, P. Taberna, S. H. Tolbert, H. D. Abruña, P. Simon and B. Dunn, Nat. Mater., 2013, 12, 518.

48 Y. L. Zheng Chen, V. Augustyn, X. Jia, Q. Xiao and B. Dunn, ACS Nano, 2012, 6, 4319-4327.

49 S. Devaraj and N. Munichandraiah, J. Mater. Chem. C, 2008, 112, 4406-4417.

50 V. A. Online, G. Binitha, M. S. Soumya, A. A. Madhavan, P. Praveen, A. Balakrishnan, K. R. V. Subramanian, M. V. Reddy, S. V. Nair, A. S. Nair and N. Sivakumar, J. Mater. Chem. A, 2013, 1, 11698-11704.

51 X. Zhang, L. Hou, A. Ciesielski and P. Samorì, Adv. Energy Mater., 2016, 6, 1600671.

52 L. Ma, X. Zhou, L. Xu, X. Xu, L. Zhang, C. Ye, J. Luo and W. Chen, Colloids Surf., A, 2015, 481, 609-615.

53 B. Desbat and J. C. Lassegues, J. Solid State Chem., 1987, 67, 235-247.
54 X. H. Guan, Z. W. Zhang, L. Yang and G. S. Wang, ChemPlusChem, 2017, 82, 1174-1181.

55 S. P. Gupta, V. B. Patil, N. L. Tarwal, S. D. Bhame, S. W. Gosavi, I. S. Mulla, D. J. Late, S. S. Suryavanshi and P. S. Walke, Mater. Chem. Phys., 2019, 225, 192-199.

56 M. Han, Y. Mu and J. Yu, Mater. Adv., 2020, 1, 421-429.

57 Y. Zhu, C. Xia, Y. Lei, N. Singh, U. Schwingenschlögl and H. N. Alshareef, Nano Energy, 2019, 56, 357-364.

58 H. Kanoh, W. Tang, Y. Makita and K. Ooi, Langmuir, 1997, 7463, 6845-6849.

59 K. S. Kumar, N. Choudhary, Y. Jung and J. Thomas, ACS Energy Lett., 2018, 3, 482-495.

60 A. Vlad, N. Singh, J. Rolland, S. Melinte and P. M. Ajayan, Sci. Rep., 2014, 4, 4315.

61 H. Vogh, Electrochim. Acta, 1994, 39, 1981-1983.

62 S. P. Gupta, S. W. Gosavi, D. J. Late, Q. Qiao and P. S. Walke, Electrochim. Acta, 2020, 354, 136626.

63 J. Jia, X. D. Liu, X. Li, L. Cao, M. Zhang, B. Wu, X. D. Liu, X. Li, L. Cao, M. Zhang, B. Wu and X. Zhou, J. Alloys Compd., 2020, 823, 153715.

64 X. Xu, R. Zhao, B. Chen, L. Wu, C. Zou, W. Ai, H. Zhang, W. Huang and T. Yu, Adv. Mater., 2019, 31, 1900526.

65 H. Peng, G. Ma, K. Sun, J. Mu, M. Luo and Z. Li, Electrochim. Acta, 2014, 147, 54-61.

66 K. H. Chang, C. C. Hu, C. M. Huang, Y. L. Liu and C. I. Chang, J. Power Sources, 2011, 196, 2387-2392.

67 V. D. Nithya, R. K. Selvan, D. Kalpan, L. Vasylechko and C. Sanjeeviraj, Electrochim. Acta, 2013, 109, 720-731.

68 S. H. Park, Y. H. Kim, T. G. Lee, H. K. Shon, H. M. Park and J. Y. Song, Mater. Res. Bull., 2012, 47, 3612-3618.

69 W. Xiao, W. Liu, X. Mao, H. Zhu and D. Wang, J. Mater. Chem. A, 2013, 1, 1261-1269.

70 L. Ma, X. Zhou, L. Xu, X. Xu, L. Zhang, C. Ye, J. Luo and W. Chen, Colloids Surf., A, 2015, 481, 609-615.

71 C. Peng, Y. Yang, C. Li, Y. Lin, R. Zheng, Z. Kuai, S. Chen, R. Li and L. Li, Nanotechnology, 2020, 31, 27.

72 P. A. Shinde, Y. Seo, C. Ray and S. C. Jun, Electrochim. Acta, 2019, 308, 231-242. 